\title{
An autopsy-proven case of Corticobasal degeneration heralded by Pontine infarction
}

\author{
Dallah Yoo', Sung-Hye Park², Sungwook Yu ${ }^{3}$ and Tae-Beom Ahn ${ }^{1 *}$ (1)
}

\begin{abstract}
Background: Neurodegenerative disorders are characterized by insidious progression with poorly-delineated long latent period. Antecedent clinical insult could rarely unmask latent neurodegenerative disorders. Here, we report an autopsy-proven case of corticobasal degeneration which was preceded by a lacunar infarction.

Case presentation: A 58-year-old man presented with acute ataxia associated with a lacunar infarction in the right paramedian pons. His ataxia persisted with additional progressive gait difficulty and left arm clumsiness. Six months later, a follow-up neurological examination showed asymmetrical bradykinesia, apraxia, dystonic posturing, postural instability, and mild ataxia of the left limbs. Cognitive examination revealed frontal executive dysfunction and visuospatial difficulties. Dopamine transporter imaging scan demonstrated bilateral reduced uptakes in mid-toposterior putamen, more prominent on the right side. Levodopa-unresponsive parkinsonism, asymmetric limb dystonia, and ideomotor apraxia became more conspicuous, while limb ataxia gradually vanished. The patient became unable to walk without assistance after 1 year, and died 4 years after the symptom onset. Autopsy findings showed frontoparietal cortical atrophy, ballooned neurons, and phosphorylated tau-positive astrocytic plaques and neuropil threads with gliosis and neuronal loss, confirming the corticobasal degeneration.
\end{abstract}

Conclusions: The case illustrates that precedent clinical events such as stroke might tip a patient with subclinical CBS into overt clinical manifestations.

Keywords: Corticobasal degeneration, Stroke, Autopsy, Case report

\section{Background}

Corticobasal degeneration (CBD) is a pathologic entity characterized by widespread tau-immunoreactive depositions in neurons and glia with a specific topographical distribution [1]. The clinical presentation of CBD is a variable combination of asymmetrical akinetic-rigid syndrome, ideomotor limb apraxia, and other clinical features including cortical sensory deficits, dystonic posturing, myoclonus, and cognitive impairment [2]. Although clinical phenotypes

\footnotetext{
* Correspondence: taebeom.ahn@khu.ac.kr

'Department of Neurology, Kyung Hee University Hospital, Kyung Hee University College of Medicine, 23 Kyungheedae-ro, Dongdaemun-gu, Seoul 02447, Republic of Korea

Full list of author information is available at the end of the article
}

of $\mathrm{CBD}$ are heterogeneous in clinicopathologic studies, none has been reported clinical evolution of CBD consecutive to precedent non-neurodegenerative event [3]. Here, we report an autopsy-proven case of CBD which was preceded by a lacunar infarction.

\section{Case presentation}

A 58-year-old right-handed man visited our hospital because of acute development of incoordination of gait and left limbs. Neurological examination showed left limb ataxia with an acute paramedian pontine infarction in brain magnetic resonance imaging (Fig. 1a to b; diffusion-weighted and fluid-attenuated inversion recovery imaging, respectively). He was an ex-smoker and had

(C) The Author(s). 2021 Open Access This article is licensed under a Creative Commons Attribution 4.0 International License, which permits use, sharing, adaptation, distribution and reproduction in any medium or format, as long as you give appropriate credit to the original author(s) and the source, provide a link to the Creative Commons licence, and indicate if changes were made. The images or other third party material in this article are included in the article's Creative Commons licence, unless indicated otherwise in a credit line to the material. If material is not included in the article's Creative Commons licence and your intended use is not permitted by statutory regulation or exceeds the permitted use, you will need to obtain permission directly from the copyright holder. To view a copy of this licence, visit http://creativecommons.org/licenses/by/4.0/ The Creative Commons Public Domain Dedication waiver (http://creativecommons.org/publicdomain/zero/1.0/) applies to the data made available in this article, unless otherwise stated in a credit line to the data. 

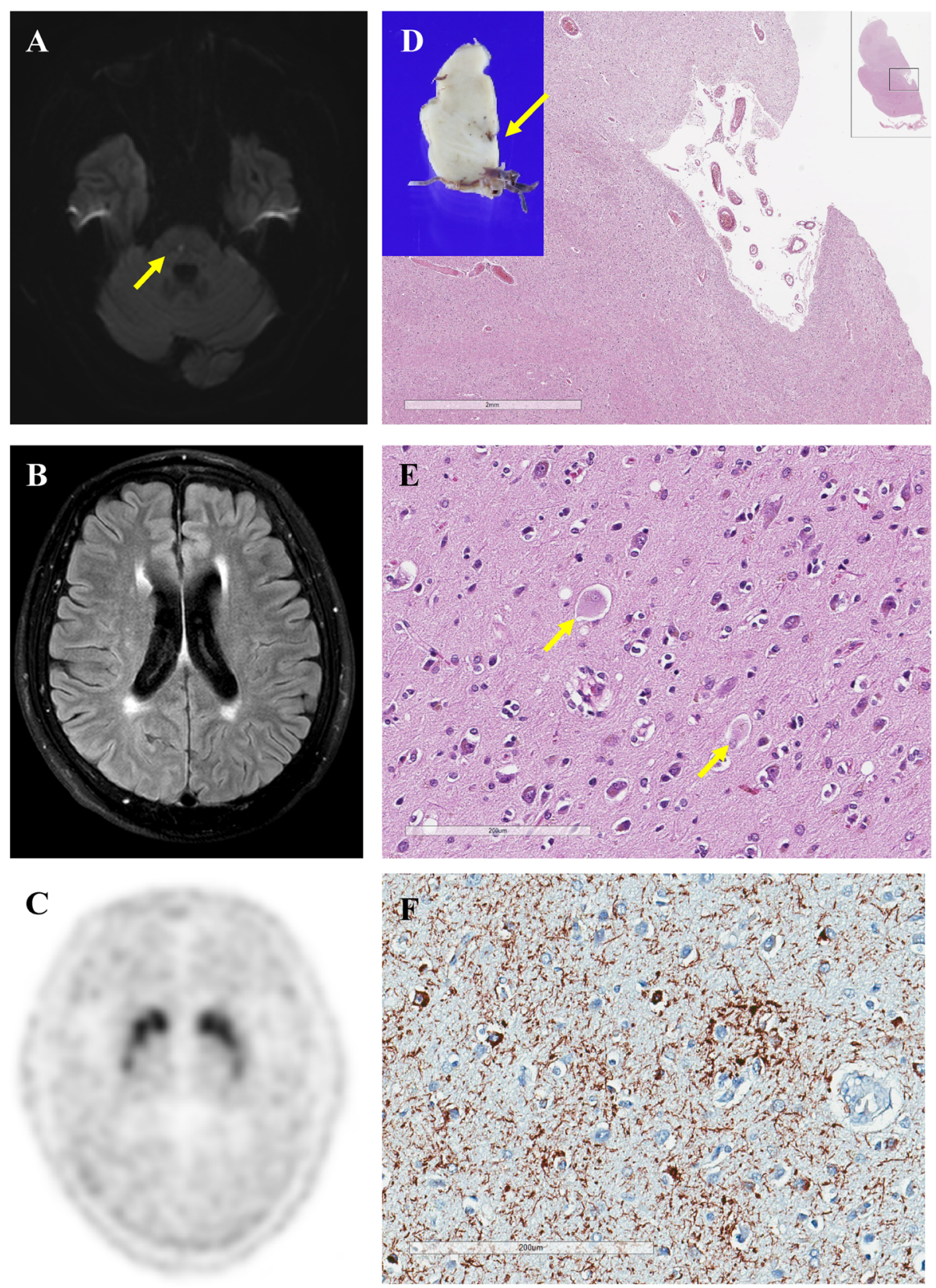

Fig. 1 Brain imaging and autopsy findings. Focal diffusion restriction is found on the right paramedian pons on diffusion-weighted imaging (a, arrow). No asymmetrical cortical atrophy is found in fronto-parietal lobe on fluid attenuated inversion recovery imaging (b). Bilateral decreased uptakes of dopamine transporters are found on positron emission tomography using 18F-N-3-fluoropropyl-2 $\beta$-carboxymethoxy-3 $\beta$-(4-iodophenyl)nortropane (c). Microscopic findings of the pontine lesion (arrow on macroscopic brain slice in the left upper corner) showed lacunar infarct with remaining blood vessels (Haemotoxylin and Eosin, (h\&e)) (d). Ballooned neurons are seen in the neocortex (arrow, h\&e) (e) Antiphosphorylated tau antibody is positive for neuronal cytoplasm, bunch of neuropil threads, and astrocytic plaques (AT8) (f)

no hypertension and diabetes mellitus. For the next six months, he was treated with antiplatelet but had complained progressive gait difficulty and aggravated dexterity of his left limbs. A follow-up neurological examination showed asymmetrical bradykinesia, apraxia, dystonic posturing, postural instability, and ataxia of the left limbs
(Supplementary Video, Part A). Cognitive function was impaired with a Korean version of the Mini-Mental Status Examination score of $21 / 30$ and a Frontal Assessment Battery score of $8 / 18$. Positron emission tomography using ${ }^{18} \mathrm{~F}-\mathrm{N}$-3-fluoropropyl-2 $\beta$-carboxymethoxy-3 $\beta$-(4-iodophenyl)-nortropane showed decreased dopamine transporter 
bindings in both mid-to-posterior putamen, more apparent on the right side (Fig. 1c). Levodopa was ineffective up to $600 \mathrm{mg}$ per day. Left-limb dystonia and apraxia became more conspicuous, while limb ataxia vanished. The patient was unable to walk without assistance one year later (Supplementary Video, Part B) and died four years after the onset.

On autopsy, gross examination showed cortical atrophy in the parietal and frontal lobes. Microscopic examination of the medial pontine lesion of the lacunar infarct showed tissue loss with remnant blood vessels (Fig. 1d, arrow on the brain slice, Haemotoxylin and Eosin, (H\&E)). Astrocyte plaques and coiled bodies were found in ballooned neurons, gliosis, and neuronal loss in the parietal lobe, motor cortex, cingulate gyrus, and hippocampus (Fig. 1e, h\&e). Phosphorylated tau-positive neuropil threads and astrocytic plaques were found in the frontoparietal lobes, cingulate gyrus, hippocampus, basal ganglia, thalamus, brainstem, and cerebellum (Fig. 1f, AT8). There were no inclusions stained with antibodies against $\beta$-amyloid, $\alpha$-synuclein, or TAR DNA binding protein 43(TDP-43).

\section{Discussion and conclusions}

Clinical features are summarized as acute pontine infarction and later presentation of levodopa-unresponsive asymmetric parkinsonism, dystonia, and apraxia, which are compatible with the clinical diagnosis of CBD [2].

It is worth noticing the initial presence of cerebellar ataxia. To our knowledge, there was only one case with pathologically confirmed CBD with prominent cerebellar ataxia in which TDP-43 co-existed [4]. In our case, ataxia developed as a clinical manifestation of acute pontine infarction rather than a de novo contribution of CBD. The rapid evolution of CBD, provoked by the precedent infarction, replaced ataxia with dystonia.

The mechanism of CBD flare-up after cerebral infarction remains speculative. It is more likely that aberrant pathologic network associated with tau-related neurodegeneration in CBD have constructed for years before the presentation. According to the model of cortico-basal ganglia-cerebellar connectome, an acute infarction in the pons could be detrimental to subclinical aberrant network responsible for CBD, turning latent abnormalities into clinical manifestation [5]. Alternatively, it was reported that tau protein increased in the cerebrospinal fluid after acute ischemic stroke [6]. Increased burden of tau might have provided a link between the infarction and CBD.

In the case of Parkinson's disease (PD), some clinical events such as subdural hematoma or the use of dopamine receptor blocking agents could uncover latent PD [7]. In CBD, this is the first autopsy-confirmed CBD case unmasked by precedent cerebral infarction.

\section{Supplementary Information}

The online version contains supplementary material available at https://doi. org/10.1186/s12883-021-02178-9.

Additional file 1.

Abbreviations

CBD: Corticobasal Degeneration; TDP-43: TAR DNA binding protein-43; H\&E: Haemotoxylin and Eosin; PD: Parkinson's disease

\section{Acknowledgements}

We appreciate the patient and his family for their contribution to this report.

\section{Authors' contributions}

SY and TA recruited the patient and dealt with the acquisition and interpretation of data; SP performed and interpreted the pathologic examinations; DY wrote the first draft of the manuscript; TA reviewed the literature and critically revised the draft; The authors read and approved the final manuscript.

Funding

Not applicable.

Availability of data and materials

All data generated or analyzed during this study are included in this published article.

\section{Declarations}

Ethics approval and consent to participate

The autopsy was permitted by his family members and conducted under the approved protocol by local ethics committee (Seoul National University Hospital).

\section{Consent for publication}

The study has been conducted in accordance with The Code of Ethics of the World Medical Association (Declaration of Helsinki), the informed consent from the patient to participate in the study was waived by local ethics committee (Kyung Hee University Hospital), and the written consent for publication was obtained from the kin of the patient.

\section{Competing interests}

The authors declare that they have no competing interests.

\section{Author details}

${ }^{1}$ Department of Neurology, Kyung Hee University Hospital, Kyung Hee University College of Medicine, 23 Kyungheedae-ro, Dongdaemun-gu, Seoul 02447, Republic of Korea. ${ }^{2}$ Department of Pathology, Seoul National University Hospital, Seoul National University College of Medicine, Seoul, Republic of Korea. ${ }^{3}$ Department of Neurology, Korea University Hospital, Korea University College of Medicine, Seoul, South Korea.

Received: 13 December 2020 Accepted: 29 March 2021

Published online: 06 April 2021

\section{References}

1. Dickson DW, Bergeron C, Chin SS, Duyckaerts C, Horoupian D, Ikeda K, et al. Office of Rare Diseases Neuropathologic Criteria for Corticobasal degeneration. J Neuropathol Exp Neurol. 2002;61(11):935-46. https://doi. org/10.1093/jnen/61.11.935.

2. Armstrong MJ, Litvan I, Lang AE, Bak TH, Bhatia KP, Borroni B, et al. Criteria for the diagnosis of corticobasal degeneration. Neurology. 2013;80(5):496503. https://doi.org/10.1212/WNL.0b013e31827fofd1.

3. Litvan I, Agid Y, Goetz C, Jankovic J, Wenning GK, Brandel JP, et al. Accuracy of the clinical diagnosis of Corticobasal degeneration. A Clinicopathologic Study. 1997;48(1):119-25. https://doi.org/10.1212/wnl.48.1.119.

4. Kouri N, Oshima K, Takahashi M, Murray ME, Ahmed Z, Parisi JE, et al. Corticobasal degeneration with olivopontocerebellar atrophy and TDP-43 pathology: an unusual clinicopathologic variant of CBD. Acta Neuropathol. 2013;125(5):741-52. https://doi.org/10.1007/s00401-013-1087-8. 
5. Quartarone A, Cacciola A, Milardi D, Ghilardi MF, Calamuneri A, Chillemi G et al. New insights into cortico-basal-cerebellar connectome: clinical and physiological considerations. Brain. 2019;143(2):396-406. https://doi.org/10.1 093/brain/awz310.

6. Hesse C, Rosengren L, Vanmechelen E, Vanderstichele H, Jensen C, Davidsson P, et al. Cerebrospinal fluid markers for Alzheimer's disease evaluated after acute ischemic stroke. J Alzheimers Dis. 2000;2(3-4):199-206. https://doi.org/10.3233/jad-2000-23-402.

7. Diaz-Corrales FJ, Sanz-Viedma S, Garcia-Solis D, Escobar-Delgado T, Mir P. Clinical features and 1231-FP-CIT SPECT imaging in drug-induced parkinsonism and Parkinson's disease. Eur J Nucl Med Mol Imaging. 2010; 37(3):556-64. https://doi.org/10.1007/s00259-009-1289-4.

\section{Publisher's Note}

Springer Nature remains neutral with regard to jurisdictional claims in published maps and institutional affiliations.

Ready to submit your research? Choose BMC and benefit from:

- fast, convenient online submission

- thorough peer review by experienced researchers in your field

- rapid publication on acceptance

- support for research data, including large and complex data types

- gold Open Access which fosters wider collaboration and increased citations

- maximum visibility for your research: over $100 \mathrm{M}$ website views per year

At BMC, research is always in progress.

Learn more biomedcentral.com/submissions 